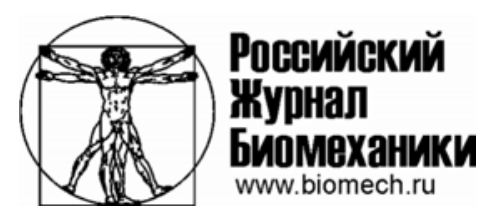

\title{
ДИНАМИКА БИОМЕХАНИЧЕСКИХ СВОЙСТВ КОЖНЫХ ПОКРОВОВ, СТЕНОК АРТЕРИЙ И СКЕЛЕТНЫХ МЫШЦ ПРИ УВЕЛИЧЕНИИ ПРОДОЛЬНЫХ РАЗМЕРОВ КОНЕЧНОСТИ
}

\begin{abstract}
B.А. Щуров
Российский научный центр «Восстановительная травматология и ортопедия» имени акад. Г.А. Илизарова» Министерства здравоохранения Российской Федерации, Россия, 640014, Курган, ул. М. Ульяновой, 6, e-mail: shchurovland@mail.ru
\end{abstract}

\begin{abstract}
Аннотация. Проведен сравнительный анализ динамики биомеханических свойств стенок сосудов, кожных покровов и скелетных мышц нижних конечностей при увеличении продольных размеров голени и бедра в процессе естественного роста у детей и при оперативном удлинении по методу Илизарова на 10-30\% от первоначальной длины. С помощью оригинальных методов исследованы эти свойства артерий, кожи и мышц у 450 здоровых людей в возрасте от 7 до 23 лет и 197 пациентов с врожденными укорочениями нижних конечностей. Показано, что у здоровых детей пропорциональность между увеличением длины конечности и увеличением показателей упругих свойств стенок артерий сохраняется до 6 лет, кожных покровов - до 10 лет и скелетных мышц - до 18 лет. Сразу после оперативного удлинения конечности показатели биомеханических свойств кожных покровов и мышц становятся больше исходных величин, а сила мышц снижается. В отдаленные сроки после лечения биомеханические показатели мягких тканей приближаются к уровню показателей, характерных для здоровых сверстников. Тем не менее сократительная способность мышц восстанавливается сравнительно медленно и лишь в отдаленные сроки после окончания лечения. Темпы такого восстановления зависят от величины удлинения конечности и выше у более молодых пациентов.
\end{abstract}

Ключевые слова: биомеханика тканей, поперечная твердость мышц, динамометрия, рост детей, удлинение конечностей.

\section{ВВеДЕНИЕ}

У здоровых детей процессы роста и развития функций осуществляются практически синхронно. В то же время известно, что после оперативного удлинения отстающей в росте конечности на большие величины практически нет проблем с кровоснабжением ее тканей, сохраняются рубцы на кожных покровах в местах проведения спиц и существенно снижается сократительная способность мышц. Чтобы понять причину асинхронности восстановительных процессов в различных тканях, нами проведено сравнительное исследование динамики биомеханических свойств стенок артерий, кожных покровов и мышц голени у здоровых детей и у больных в условиях естественного продольного роста и при оперативном удлинении пораженной конечности. Теоретическое обоснование оперативного увеличения размеров конечностей дано Г.А. Илизаровым [1] в открытом им законе о стимулирующем влиянии возникающего при дистракции напряжения растяжения тканей на их регенерацию и рост.

(C) Щуров B.А., 2015

Щуров Владимир Алексеевич, д.м.н., профессор, г.н.с. лаборатории исправления деформаций и удлинения конечностей, Курган 
Целью исследования явился не только сравнительный анализ динамики биомеханических свойств артерий, кожных покровов и мышц конечности в условиях естественного роста и после их оперативного удлинения, но и оценка уровня восстановления сократительной способности мышц у больных после лечения.

\section{МАТЕРИАЛ И МЕТОДЫ ИССЛЕДОВАНИЯ}

Комплексно обследованы 450 здоровых детей в возрасте от 7 до 23 лет и 197 больных с врожденными укорочениями нижних конечностей до лечения, в ближайшие 6 месяцев и в отдаленные сроки после окончания удлинения с помощью метода чрескостного остеосинтеза отстающей в росте нижней конечности на 10-30\% от исходной длины за счет увеличения продольных размеров бедра и голени. Средний возраст больных при обследовании в ближайшие 6 месяцев после окончания лечения составил $13,2 \pm 0,8$ г.

О биомеханических свойствах артерий конечности судили по величине скорости распространения артериальной пульсовой волны $(V, \mathrm{~cm} / \mathrm{c})$, отражающей модуль упругости стенок сосудов мышечного типа [10]. Оцениваемое расстояние от щели коленного сустава до внутренней лодыжки, где располагались сфигмографические датчики, сопоставляли с разницей времени начала анакроты пульсовой волны подколенной артерии и задней большеберцовой артерии [4].

Исследование упруго-эластических свойств кожи проводили с помощью разработанного авторами устройства [8]. В простейшей схеме эластометра момент силы прилагают к поверхности кожи через предварительно покрытый адгезивным материалом опорный диск диаметром 2 см (рис. 1). Способ основан на оценке величины ротации участка кожных покровов при приложении тангенциально направленного усилия с моментом $6 \mathrm{H} \cdot \mathrm{cm}$ и стандартной величине прилагаемого осевого давления, достаточного для надежного сцепления накладного диска и поверхности кожи. Устройство состоит из стержня, являющегося осью, на одном конце которого неподвижно укреплен опорный диск, а на другом - подвижно металлическая пластинка. На секторе нанесена шкала в градусах. Стрелка служит для отсчета угла ротации накладного диска под влиянием прилагаемого момента силы. Плоская пружина неподвижно соединена со стержнем. Вторая стрелка и шкала предназначены для контроля необходимого вращающего момента силы.

При тестировании кожных покровов моментами силы в диапазоне 5-10 Н·см связь между моментом силы, площадью накладного диска и углом ротации кожи может быть описана с точностью $\pm 5 \%$ следующей приближенной зависимостью: $E=M /(a \cdot S)$, где $E$ - показатель упругости кожи; $M$ - момент силы; $a$ - угол ротации кожи; $S$ площадь опорного диска. В пределах действующих сил угол ротации кожи пропорционален прилагаемому моменту силы и обратно пропорционален площади накладного диска и упруго-эластическим свойствам кожных покровов. Размерность показателя эластичности кожи выражают в г/(см·град). При постоянном моменте силы и площади накладного диска показатель $E$ обратно пропорционален углу ротации кожи. Исследование упруго-эластических свойств кожного покрова средней трети задней поверхности голени проводили в состоянии физического покоя, в положении обследуемого лежа на животе.

Оценка показателя упругости (поперечной твердости) икроножной мышцы осуществлялась с помощью механического миотонометра (рис. 2), выполненного на базе индикатора перемещения часового типа с ценой деления 0,01 мм, на ножке которого крепится опорный цилиндр с наружным диаметром 20 мм, а внутри цилиндра находится подвижный шток с опорной пяткой диаметром 5 мм. Величина подъема штока при опускании устройства массой 250 г на поверхность стекла $-4,35$ мм. 


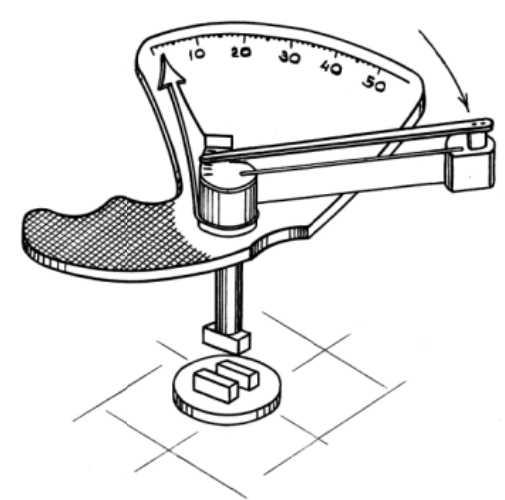

Рис. 1. Принципиальная схема устройства для измерения эластичности кожных покровов

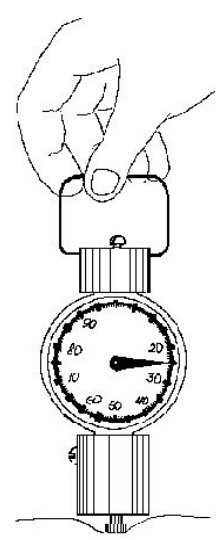

Рис. 2. Схема, поясняющая способ определения поперечной твердости мышц

Исследование проводилось в состоянии покоя, с использованием подставки под дистальный отдел стопы, исключающей упор переднего отдела стопы в поверхность кушетки. Величина подъема штока в сотых долях мм при опускании устройства на наружное брюшко икроножной мышцы принималась за показатель ее упругости и выражалась в условных единицах. У здоровых детей показатель увеличивался по мере увеличения длины голени от 0 усл. ед. и достигал у женщин 20-40 лет 75-100 усл. ед., у мужчин того же возраста - 100-150 усл. ед. [9].

Исследование внутримышечного давления выполнено у добровольно давших согласие на исследование 30 здоровых людей и 33 больных в процессе лечения. Метод основан на том, что через иглу диаметром 0,8 и длиной 60 мм в мышцу по ходу волокон вводится 1 мл стерильного изотонического раствора. Затем в ту же область с помощью вращающегося с постоянной скоростью эксцентрического толкателя со скоростью 2 мл/мин порциями по 0,5 мл вводится физиологический раствор с минутным интервалом. С помощью манометра «Gould» $P 23$ ID (США) регистрируются ступенчато возрастающие величины внутритканевого давления [6]. Из полученных величин вычитается значение предварительно определенного давления, обусловленного гидродинамическим сопротивлением измерительной системы. Затем строится график зависимости давления от объема жидкости и определяется то давление, которое должно быть в ткани до начала введения раствора.

Определение внутримышечного давления у обследуемых позволило построить график взаимосвязи этого показателя и показателя поперечной твердости мышц (рис. 3). Между показателями выявлена высокая степень корреляционной взаимосвязи.

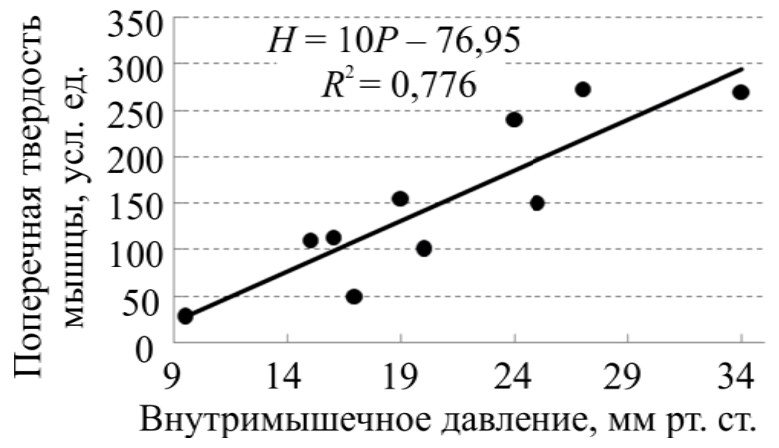

Рис. 3. Взаимосвязь между величиной поперечной твердости брюшка икроножной мышцы и внутримышечным давлением в мышце у здоровых обследуемых и у больных при удлинении голени 


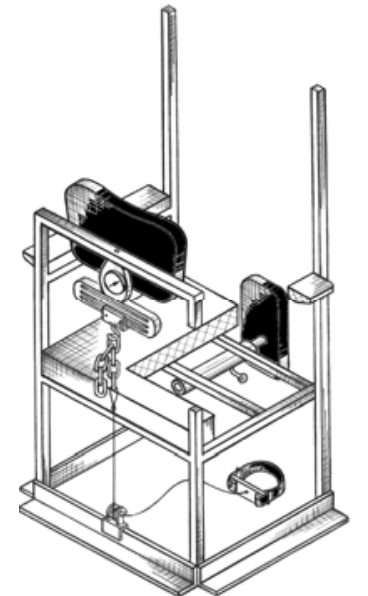

Рис. 4. Схема динамометрического стенда для определения момента силы передней и задней групп мышц бедра. Сила мышцразгибателей определяется в положении сидя, мышц-сгибателей - в позе стоя лицом к стенду с упором коленом в выдвижной торец

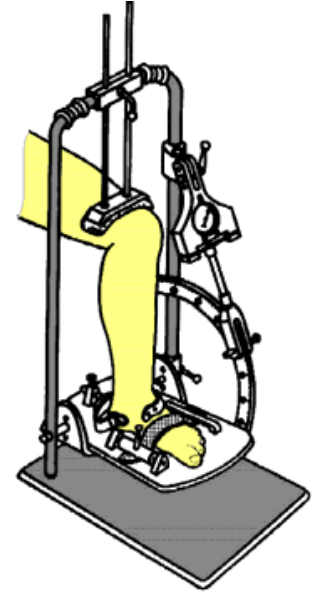

Рис. 5. Схема динамометрического стенда для определения момента силы мышц голени. Ось вращения голеностопного сустава совпадает с осью подвески стенда. Угол в коленном суставе $-90^{\circ}$, возможно изменение установки угла в голеностопном суставе от 80 до $115^{\circ}$

Определение максимального момента силы мышц-сгибателей и разгибателей стопы осуществлялось с помощью динамометрических стендов (рис. 4 и 5) [5, 7]. Чтобы исключить влияние на показатели увеличивающейся с возрастом массы тела, мы использовали относительные показатели момента силы мышц, выражающиеся в H·м на 1 кг массы тела.

Статистическая обработка результатов исследований проводилась с помощью пакета анализа данных Microsoft Excel 2010. Для оценки достоверности различий результатов использовали $t$-критерий Стьюдента. Применяли методы корреляционного и регрессионного анализа с определением соответственно коэффициентов корреляции $r$ и индекса детерминации $R^{2}$.

\section{РЕЗУЛЬТАТЫ ИССЛЕДОВАНИЯ И ИХ ОБСУЖДЕНИЕ}

Величина скорости распространения пульсовой волны $(V, \mathrm{~cm} / \mathrm{c})$, отражающая упруго-эластические свойства стенок артерий, у детей до 6 лет увеличивалась по мере прироста длины голени (рис. 6). В дальнейшем величина $V$ определялась уже количеством прожитых лет. У больных детей $V$ возрастала после оперативного изменения продольных размеров голени. В процессе дистракции, в отличие от биомеханических параметров других тканей, величина $V$ существенно не изменялась, поскольку сохранение просвета приносящих кровь артерий обеспечивает кровоснабжение тканей.

Показатель эластичности кожных покровов $E$ у здоровых детей увеличивался пропорционально приросту длины голени до 10 лет. У больных этот показатель ниже нормы и возрастал после оперативного увеличения длины конечности, достигая расчетных значений в отдаленные сроки (более 1 года) после лечения (рис. 7).

В отличие от стенок артерий и кожных покровов, биомеханические свойства мышц нижних конечностей определялись их продольными размерами до окончания периода естественного продольного роста (до 18 лет). Эта пропорциональность сохранялась, в том числе у больных с гипофизарным гигантизмом (при увеличении длины голени до 60 см). 


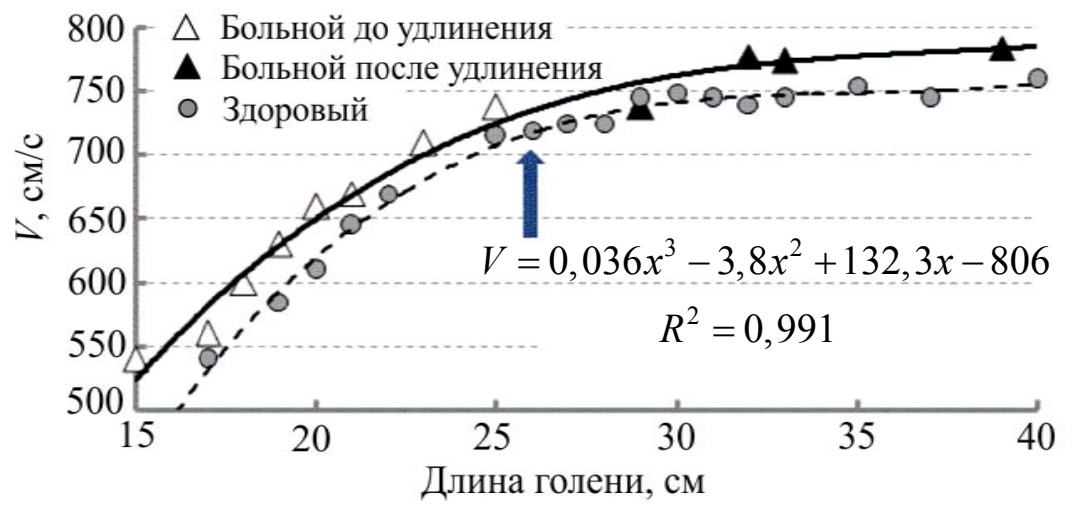

Рис. 6. Зависимость показателя тонуса стенок артерий от длины голени у здоровых обследуемых и у больных до и после (после стрелки) удлинения конечности

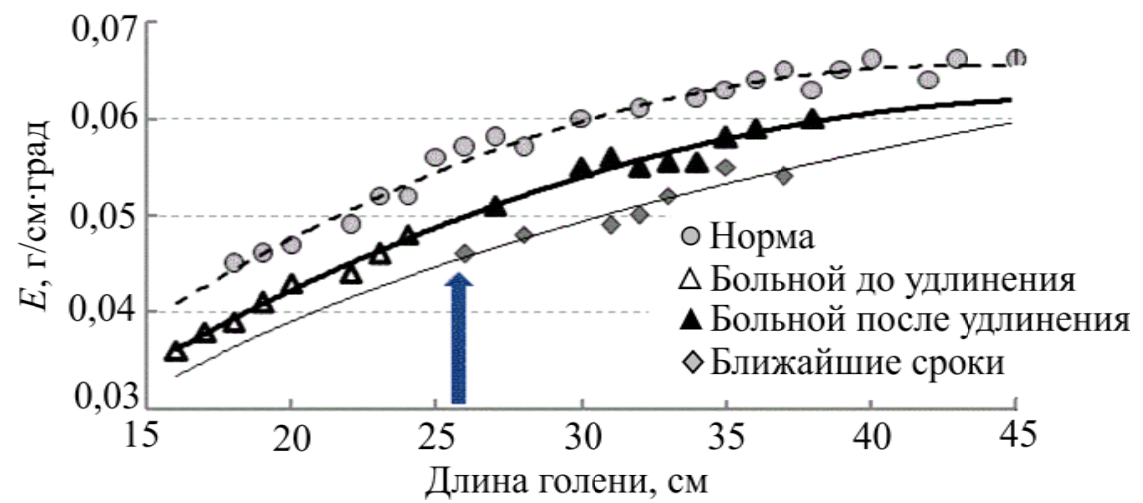

Рис. 7. Показатель упругости кожных покровов голени в норме и у больных до лечения, по истечении восстановительного периода после лечения и ближайшие сроки после удлинения голени

При удлинении голени при дистракции показатель упругости задней группы мышц голени возрастал на $346 \%$ по сравнению с исходным уровнем. Обхват голени при этом становился больше на 3 см. Такой прирост показателя поперечной твердости мышц обусловлен также изменением гидратации тканей.

После окончания удлинения голени в течение всего периода фиксации величина показателя упругости мышц снижалась, оставаясь значительно выше исходных значений (183 \pm 8 усл. ед.) вследствие сохраняющейся повышенной гидратации тканей. В дальнейшем, в отдаленные сроки после лечения (более года), показатель после снятия аппарата приближался к уровню, соответствующему здоровым сверстникам с такими же продольными размерами нижних конечностей (рис. 8).

У детей, в отличие от подростков, в процессе естественного продольного роста конечности происходило самопроизвольное увеличение не только длины кости, но и сократительной части мышц [9, 11], поэтому показатель их поперечной твердости оставался сравнительно низким.

В подростковом возрасте под влиянием скачка роста начиналось существенное увеличение напряжения растяжения мышц. Такая же картина наблюдалась и при оперативном удлинении конечности, но темп увеличения размеров в этом случае выше примерно в 30 раз и, соответственно, в 2-3 раза больше напряжения растяжения тканей. Для мышц при их сокращении увеличение напряжения растяжения сухожилий - обычный момент их работы и не является стимулом для регенерации и роста. Пластические возможности соединительнотканых элементов значительно ниже, поэтому полная компенсация возросших показателей упругости мышц за счет 


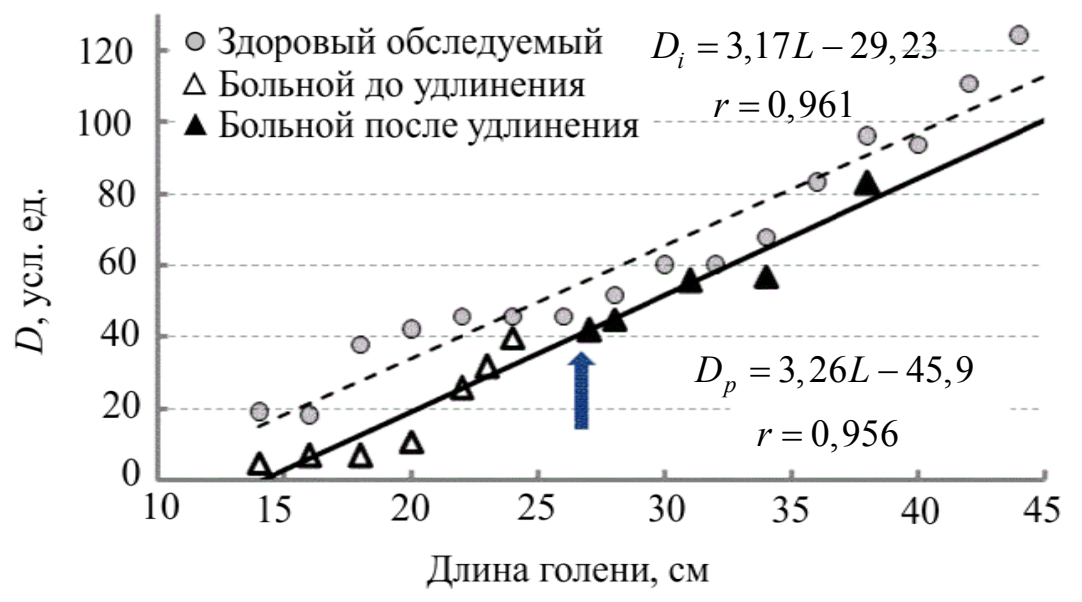

Рис. 8. Зависимость показателя поперечной твердости мышц от продольных размеров голени у здоровых обследуемых и у больных до и после (после стрелки) удлинения голени

продольного роста сухожильной части мышц происходила в ближайшие месяцы после окончания периода дистракции и проявлялась в восстановлении амплитуды изменения длины сократительной части мышц (амплитуда движений в суставах). При этом важно не допустить при дистракции повышения внутримышечного давления до величин перекрытия артериолярного русла (более 50 мм рт. ст.), когда показатель упругости мышц превышает 230 усл. ед. В таких случаях продолжение дистракции в том же темпе может привести к ишемии ткани и повреждению сократительных элементов.

Существует несколько способов предохранения мышц от ишемического повреждения: созданием исходного запаса свободного хода мышц за счет изменения угла установки в суставе при наложении аппарата, фармакологическое снижение величины напряжения растяжения мышц, высокодробная дистракция на протяжении суток (1 мм за 60 приемов в сутки [3]). В период лечения важно осуществлять контроль за состоянием упругости удлиняемых мышц и кровоснабжением конечности, за самочувствием и уровнем системного артериального давления у больного.

Сократительная способность мышц нижних конечностей является важнейшим показателем функционального состояния опорно-двигательной системы. В условиях естественного роста у детей и подростков сила мышц бедра и голени увеличивается пропорционально изменению продольных размеров этих сегментов конечности. Однако при оперативном удлинении бедра и голени динамометрические характеристики мышц падают практически до нуля и восстанавливаются в ближайшие месяцы после окончания лечения, обычно не достигая исходных значений (табл. 1).

Наиболее существенные различия в показателях амплитуды были выявлены у больных с разной величиной удлинения в первые 4 месяца после снятия аппарата. Чем на большую величину удлинено бедро ( $X, \%$ от исходной длины), тем меньше амплитуда движений в коленном суставе ( $A$, \% от уровня нормы): $A=74,1-1,54 X$; $r=-0,997$.

При одинаковой величине удлинения бедра чем моложе были пациенты, тем быстрее и в большем объеме восстанавливалась амплитуда движений в коленном суставе. К концу 1-го года после снятия аппарата Илизарова зависимость амплитуды движений в коленном суставе от возраста пациентов описывалась уравнением регрессии $A=148-3,40 T ; r=0,720$.

Относительный момент силы передней и задней групп мышц отстающей в росте голени до лечения составлял соответственно 73 и $78 \%(p \leq 0,001)$ от уровня здоровой. В ближайшие сроки после лечения - 70 и $55 \%$, в отдаленные сроки - 71 и 81 \% (табл. 2). 
Таблиия 1

Относительный момент силы мышц бедра до и после удлинения, Н·м/кг

\begin{tabular}{|c|c|c|c|c|c|}
\hline \multirow{2}{*}{$\begin{array}{c}\text { Группа } \\
\text { обследуемых }\end{array}$} & $\begin{array}{c}\text { Число } \\
\text { наблюдений }\end{array}$ & \multicolumn{2}{|c|}{ Разгибатели голени } & \multicolumn{2}{|c|}{ Сгибатели голени } \\
\cline { 3 - 6 } & интактная & больная & интактная & больная \\
\hline До лечения & 103 & $1,63 \pm 0,08$ & $1,15 \pm 0,07^{*}$ & $1,27 \pm 0,06$ & $1,01 \pm 0,05^{*}$ \\
\hline $\begin{array}{c}\text { Ближайшие сроки } \\
\text { после лечения }\end{array}$ & 27 & $1,50 \pm 0,16$ & $0,7 \pm 0,16^{*}$ & $1,25 \pm 0,12$ & $0,81 \pm 0,15^{*}$ \\
\hline $\begin{array}{c}\text { Отдаленные сроки } \\
\text { после лечения }\end{array}$ & 27 & $1,65 \pm 0,13$ & $1,09 \pm 0,10^{*}$ & $1,37 \pm 0,12$ & $1,02 \pm 0,9$ \\
\hline
\end{tabular}

Примечание: * - отличие от уровня интактной конечности достоверно, $p \leq 0,05$.

Таблий 2

Относительный момент силы мышц голени до и после лечения, Н·м/кг

\begin{tabular}{|c|c|c|c|c|c|}
\hline \multirow{2}{*}{$\begin{array}{c}\text { Группа } \\
\text { обследуемых }\end{array}$} & \multirow{2}{*}{$\begin{array}{c}\text { Число } \\
\text { наблюдений }\end{array}$} & \multicolumn{2}{|l|}{ Тыльные сгибатели стопы } & \multicolumn{2}{|c|}{$\begin{array}{c}\text { Подошвенные сгибатели } \\
\text { стопы }\end{array}$} \\
\cline { 3 - 6 } & & интактная & больная & интактная & больная \\
\hline До лечения & 103 & $0,70 \pm 0,04$ & $0,51 \pm 0,04^{*}$ & $1,41 \pm 0,05$ & $1,10 \pm 0,07^{*}$ \\
\hline Ближайшие сроки & 27 & $0,58 \pm 0,05$ & $0,41 \pm 0,04^{*}$ & $1,26 \pm 0,09$ & $0,70 \pm 0,10^{*}$ \\
\hline Отдаленные сроки & 27 & $0,68 \pm 0,06$ & $0,48 \pm 0,05^{*}$ & $1,56 \pm 0,16$ & $1,26 \pm 0,18$ \\
\hline
\end{tabular}

Примечание: * - отличие от уровня интактной конечности достоверно, $p \leq 0,05$.

С увеличением возраста больных уровень восстановления силы мышц удлиненной конечности становился меньше (рис. 9). Поэтому удлинение конечности в раннем возрасте (до 10 лет) оправдано, поскольку после лечения продолжаются процессы естественного роста, и ткани легче адаптируются к новым биомеханическим условиям.

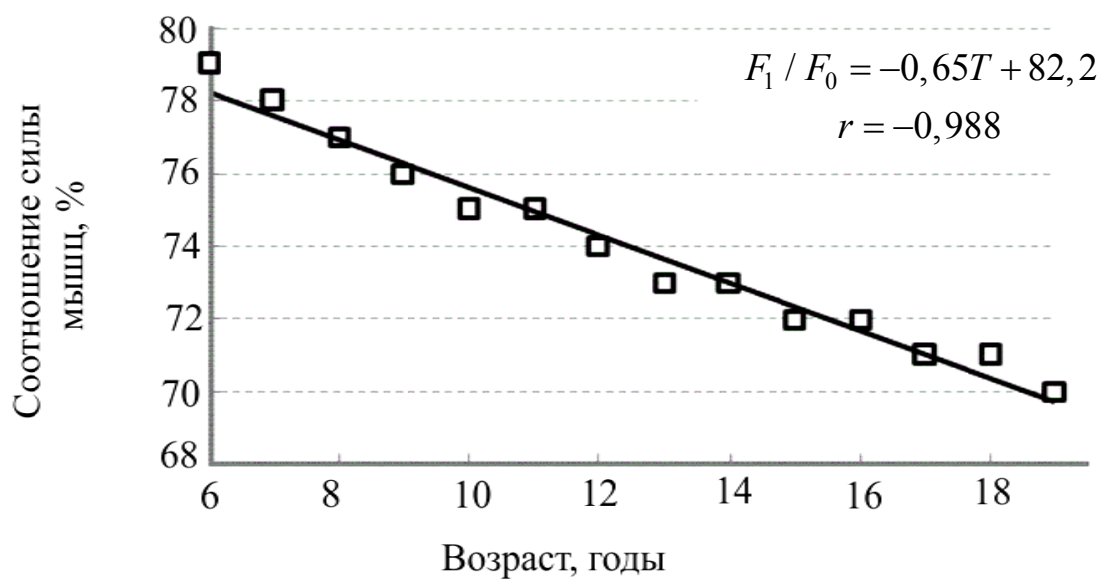

Рис. 9. Возрастная динамика соотношения момента силы задней группы мышц удлиненной и интактной конечностей 
Установлено, что чем больше отставание конечности в росте, тем ниже показатели ее силы. Взаимосвязь между величиной отставания продольных размеров пораженной голени $(L$, см) и относительным моментом силы мышц - подошвенных сгибателей стопы $(F, \mathrm{H} \cdot \mathrm{M} /$ кг) может быть описана уравнением линейной регрессии $F=1,7-0,096 L ; r=0,260$. Соответственно, чем на большую величину удлинялась голень, тем ниже уровень восстановления силы мышц.

Таким образом, по мере естественного продольного роста у пациентов происходит прирост показателей упруго-эластических свойств мягких тканей конечностей, который одновременно может свидетельствовать об уменьшении резерва их продольного роста и функционального восстановления после оперативного увеличения длины конечности. Линейная зависимость биомеханических свойств стенок артерий от продольных размеров конечности сохраняется до 6 лет, кожных покровов до 10 лет и мышц - до 18 лет. Эти различия зависимости свойств тканей от изменения размеров конечности определяют большую уязвимость мышц при дистракции, более медленные темпы функциональной реабилитации после окончания лечения.

Поэтому наиболее важное значение в ограничении масштаба изменения размеров тела больных за счет удлинения конечностей имеют прирост в процессе дистракции напряжения мышц, ухудшение их кровоснабжения и появление болевого синдрома. Ишемическое повреждение мышц вследствие возникающих трудностей кровоснабжения может привести к нарушению их структуры и в последующем к недовосстановлению сократительной способности. Поэтому при прогнозировании функциональных исходов лечения нужно учитывать не только эстетический эффект от прироста длины отстающих в росте конечностей и увеличения длины шага больных [4], но и степень снижения сократительной способности мышц, возрастающей по мере продолжения дистракции и особенно с увеличением возраста пациентов.

\section{БЛАГОДАРНОСТИ}

Автор благодарит ортопедов, член-корреспондента Российской академии наук, профессора В.И. Шевцова, профессоров А.В. Попкова, А.М. Аранович, Г.С. Джанбахишова, доктора медицинских наук К.И. Новикова и кандидата медицинских наук С.О. Мурадисинова, которые проводили лечение больных, участвовавших в биомеханическом обследовании.

\section{СПИСОК ЛИТЕРАТУРЫ}

1. Илизаров Г.А. Общебиологическое свойство тканей отвечать на дозированное растяжение ростом и регенерацией (эффект Илизарова). Диплом № 255. Заявка № 11271 от 25.12.85. Бюл. изобретателя. 1989. № 15.

2. Савицкий Н.Н. Биофизические основы кровообращения и клинические методы изучения гемодинамики. - Л., 1974. - 310 с.

3. Шевцов В.И., Попков А.В. Круглосуточное удлинение конечностей в автоматическом режиме. Курган, 2003. - С. 1-16.

4. Шевцов В.И., Щуров В.А., Менщикова Т.И. Теоретические предпосылки и практические последствия увеличения длины нижних конечностей у больных ахондроплазией // Российский журнал биомеханики. - 2000. - Т. 4, № 3. - С. 74-79.

5. Щуров В.А. Устройство для ангулодинамометрии: патент 2029536 РФ МКИ3 А61Н1/00 № 5042260/14; заявл. 15.05.92; опубл. 27.02.95. Бюл. изобр. 1995. № 6.

6. Щуров В.А., Горбачева Л.Ю., Сысенко Ю.М. Измерение давления в икроножной мышце при лечении по Илизарову больных с повреждениями голени // Вестник хирургии имени И.И. Грекова. 1994. - № 1-2. - С. 67-69.

7. Щуров В.А., Долганова Т.И., Долганов Д.В., Атманский И.А. Устройство для определения силы мышц бедра: патент на полезную модель № 35703 РФ; № 200311 8782; заявл. 10.07.04. 
8. Щуров В.А., Долганова Т.И., Щурова Е.Н. Скорость распространения пульсовой волны при изменении длины конечности и регионального артериального давления у обследуемых разного возраста // Физиология человека. - 1993. - Т. 19, № 4. - С. 64-69.

9. Щуров В.А., Кудрин Б.И., Шеин А.П. Взаимосвязь биомеханических и функциональных характеристик мягких тканей голени при ее удлинении по Илизарову // Ортопедическая травматология. - 1981. - № 10. - С. 30-34.

10. Щуров В.А., Соломка О.В. Ортостатические изменения упругости кожных покровов нижних конечностей у больных, перенесших инфаркт миокарда // Российский журнал биомеханики. - 2002. T. 6, № 4. - C. 79-83.

11. Stewart D.M. Charter 5. The role tension in muscle growth / ed. by R.J. Goss // Regulation of organ and tissue growth. - New York: Academic Press, 1972. - P. 77-100.

\section{DYNAMICS OF BIOMECHANICAL PROPERTIES OF THE SKIN, ARTERY WALLS AND SKELETAL MUSCLES AT INCREASE IN THE LONGITUDINAL SIZE OF THE EXTREMITY}

\section{V.A. Schurov (Kurgan, Russia)}

A comparative analysis of dynamics of the biomechanical properties of the vascular walls, skin and skeletal muscles of the lower extremities at an increase in the longitudinal dimensions of the tibia and femur in the process of natural growth in children and the surgical lengthening by the Ilizarov method 10-30\% of the original length was conducted. By using original methods, these properties of the arteries, skin, and muscles at 450 healthy people between the ages of 7 to 23 years and 197 patients with congenital shortening of the lower extremities were studied. It was shown that in healthy children proportionality between the increase in limb length and an increase in performance of the elastic properties of the walls artery was preserved up to 6 years, the skin - up to 10 years of age and skeletal muscles up to 18 years. Immediately after surgical limb lengthening, indicators of biomechanical properties of the skin and muscles became more of initial values, and muscle strength reduced. In the long-term period after the treatment, biomechanical performance of soft tissues was approaching the level of indicators specific to healthy children of the same age. However, the contractile ability of muscles was recovering relatively slowly and only later after the end of treatment. The pace of recovery depends on the limb lengthening and higher in younger patients.

Key words: tissue biomechanics, muscle transverse hardness, dynamometry, growth in children, lengthening limbs. 